\title{
Study on the Correlation of Wind Pressure on Cooling Tower
}

\author{
Xiangyang Ren ${ }^{1, a}$ \\ ${ }^{1}$ China Railway Construction Group Co. Ltd. \\ a19097889@qq.com
}

Keywords: Wind tunnel tests; Cooling tower; Correlation of wind pressure; Wind pressure coefficient.

\begin{abstract}
. objective: to study the surface wind pressure of cooling tower under the condition of isolated tower and adjacent two towers. Method: wind tunnel test. Process: simultaneous pressure-measured tests on the rigid model, contrast the test results of isolated tower and adjacent two towers' rigid model. Results and analysis: when Twin Towers tandem, the front tower have a greater impact on the latter tower than the latter tower has for the front one; the effect of interference is important to the flow direction; Conclusion: In this paper, the wind pressure of cooling tower is studied by wind tunnel test method.
\end{abstract}

\section{Introduction}

In recent years, with the rapid development of China's electric power industry, power plant cooling tower increase the body mass[1,2,3], and the layout is from single tower to Twin Towers, tower combination in the same time.

In this paper, the wind tunnel test method is used to obtain the table of a isolated cooling tower and wind pressure[4,5], comparing with the previous measurement[6,7], wind tunnel test data to determine the reasonable model surface roughness; analysis the law of surface wind pressure distribution changes with the distance between the tower and the wind direction that the adjacent two towers in tandem[8,9,10], parallel and diagonal case.

\section{Wind Tunnel Test of Cooling Tower}

Experimental Equipment and Model. The wind tunnel of the cooling tower test is a closed reflux type rectangular tunnel, test section size $15 \mathrm{~m}$, high $2 \mathrm{~m}$, long $14 \mathrm{~m}$. By setting the spires and roughness elements to simulate the B standard of landform, simulation results are as follows: wind profile index $a=0.15$, turbulence degree of surface $(5 \mathrm{~cm}$ height) is $15 \%$, the turbulence of the top cooling tower is $10 \%$, fluctuating wind spectrum is close to common wind spectrum model. The simulation results satisfy the requirements of B type flow field wind characteristics. Adjustment and measurement of boundary layer wind field using Streamline Hot wire gauge made by Denmark DANTEC Company. Outside surface pressure measurement of cooling tower using DSM3000 electronic pressure scanning valve made in American. Sampling frequency is $312 \mathrm{SHz}$, the total length of the sample is 6000 .

Symbol Definition. The Convention for the sign of the surface air pressure: the inward (pressure) of the relative model tower is in a positive value and the outward (suction) is in a negative value. For the convenience of the analysis, the pressure coefficient of the cooling tower is expressed as the pressure coefficient of the reference pressure, also called body coefficient.

The mean pressure coefficient $C_{p_{i}}(\theta, H)$ of cooling tower surface of each measuring point $i$ is expressed as:

$$
C_{p_{i}}(\theta, H)=\frac{P_{\mathrm{m}}(\theta, H)-P_{\infty}(H)}{P_{0}(\theta, H)-P_{\infty}(H)}
$$


In formula1: $\theta$ is the point $\mathrm{i}$ along the ring to the azimuth. $P_{\mathrm{m}}(\theta, H)$ is the average pressure of the measuring point i. $P_{0}(H)$ and $P_{\infty}(H)$ are the total pressure and static pressure at the height of the $\mathrm{i}$ in the test. The fluctuating pressure coefficient (root variance) of the measuring point $\mathrm{i}$ is $\sigma_{p}(\theta, H)$.

The outer surface of the cooling tower by measuring overall resistance points obtained (downwind) coefficient and lift coefficient (across wind) integral are defined as:

$$
\begin{aligned}
C_{D} & =\frac{\sum C_{p} A_{i} \cos \left(\theta_{i}\right)}{A_{T}} \\
C_{L} & =\frac{\sum C_{p_{i}} A_{i} \sin \left(\theta_{i}\right)}{A_{T}}
\end{aligned}
$$

In formula 2/3: $C_{D} 、 C_{L}$ are the structural overall drag force and lift coefficient, $A_{i}$ is the pressure cover area of the point $\mathrm{i}, \theta_{i}$ is the angle between the pressure and the direction of the wind axis at the point $\mathrm{i}, A_{T}$ is the overall structure of the wind axis direction projection area.

In order to reflect the influence of the adjacent cooling tower on the resistance coefficient of the tower under different wind direction and tower distance, the interference factor is defined:

$$
\mathrm{IF}=\frac{C_{D . \mathrm{g}}}{C_{D . \mathrm{s}}}
$$

In formula 4: $C_{D . g}$ is the test of resistance coefficient in combination of tower; $C_{D . s}$ is the single tower resistance coefficient.

In order to facilitate the design specification for hydraulic and wind load, equivalent ratio coefficient for multi tower:

$$
K_{m}=\frac{C_{D, \text { max }, \mathrm{s}} \times P_{\mathrm{ch}} \times K_{D} \times M_{\mathrm{if}}}{C_{D \text {,mean,s,code }} \times \beta_{\mathrm{s}, \text { code }}}
$$

In formula 5: $C_{D \text {,max,s }}$ is the extreme value of single tower resistance coefficient in turbulent flow field, combined with B class of wind profile. The drag coefficient of the single tower drag coefficient of the uniform flow field and the turbulent flow field is converted to an equivalent uniform flow field condition of $P_{\mathrm{ch}}=1.44 \mathrm{~K}_{D}$ is the ratio of the maximum drag coefficient of the wind direction in the wind tunnel test in Twin Towers and the ratio of the extreme value of the maximum drag coefficient to the extreme value of the single tower drag coefficient.

\section{Surface Wind Pressure of A Single Cooling Tower}

Single Tower Pressure Distribution. Figure 1 shows the relationship between the measured B curve $C_{p}$.of single tower in turbulent flow field in the average pressure coefficient and azimuth $\theta$. And the comparison of the wind pressure distribution curve is given.Can be seen, the results of the single tower test with the Reynolds number effect have good agreement with the standard curve, Only the wake region pressure coefficient $C_{L}$ is -0.48 , has difference with the standard curve. 


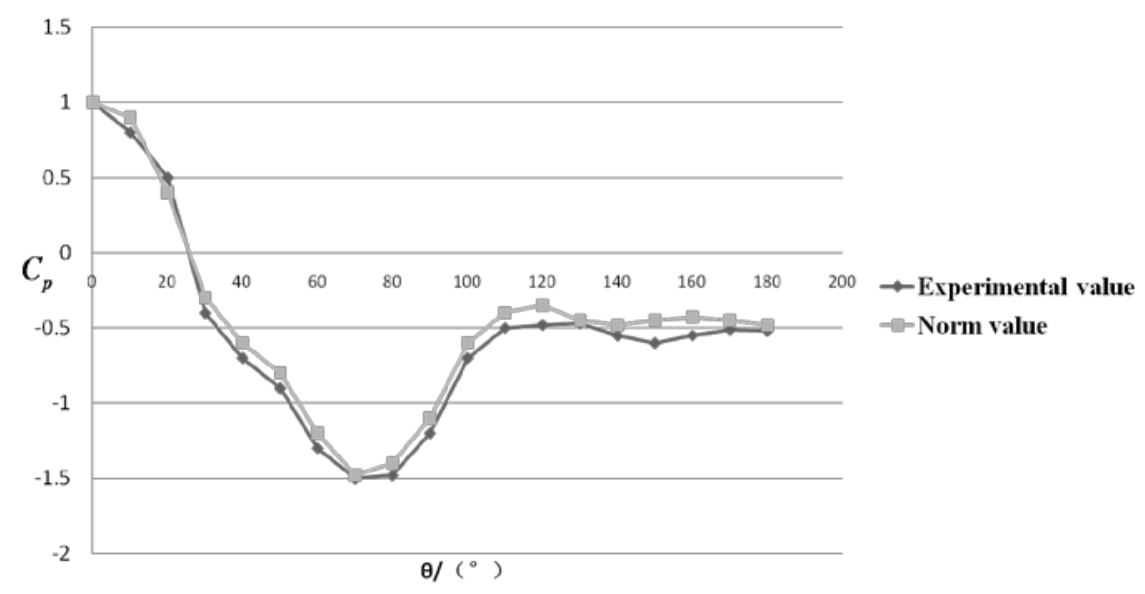

Figure 1. Relationship between average pressure coefficient and azimuth angle

The cooling tower model of meridional 12 sections along the height distribution of mean drag coefficient are end features of big middle small, the mean value of the drag coefficient at the bottom of the tower and the top of the tower is 0.542 and 0.629 , exceed $65 \%$ and $91 \%$ of the mean value of minimum drag coefficient in the middle section respectively. The characteristics of three-dimensional flow around the flow is obvious. This phenomenon is mainly due to the effect of the flow around the cooling tower, ,the stress of the bottom and the top of the tower is more complex, the local pressure coefficient is much larger than the standard design value.

Wind Pressure Characteristics Under Standard Roughness. Mean and RMS values of 110m height measurement points under standard roughness, according to the test results, the cooling tower can be divided into 3 zones, respectively for the wind zone, the separation zone and the wake zone. The average values of the body coefficient of the wind zone ( 0 degrees -40 degrees) gradually decreased, until negative pressure, and the root mean square remained unchanged; The average values of the body coefficient and the root mean square of the separation region (40 degree -110 degree) were large, and the average value reached the minimum at the circumference of 80 degrees, and the average value was 40 , and the shape coefficient was 100 at the circumference of 0.24 degrees; The average value of the body coefficient and the root mean square root of the tail flow region (110 degree -180 degree) are relatively stable.

\section{Adjacent Two Towers Overall Surface Wind Pressure}

The surface wind pressure distribution determines the overall aerodynamic drag coefficient and lift coefficient of the cooling tower. The overall aerodynamic drag coefficient of the test tower under different flow angles, lift coefficient, interference factor IF and equivalent multitower proportional coefficient.The relationship between all these factors and the tower distance: the maximum drag coefficient appears at the $90^{\circ}(\mathrm{L} / \mathrm{D} \geqslant 2)$ and $112.5^{\circ}(\mathrm{L} / \mathrm{D} \geqslant 2)$ direction of the wind direction. The other direction resistance coefficient were lower than single tower, the minimum drag coefficient in 0 degree of wind direction, Less than 60 percent of single tower.

When $\mathrm{L} / \mathrm{D} \leqslant 2$ and wind direction angle is $0^{\circ} \leqslant \beta<90^{\circ}$, with the increase of the tower distance and the flow angle, the shielding effect of the tower to the test tower is weakened, and the pressure coefficient of the surface pressure is increased, the resistance coefficient of the test tower is increasing.

When $L / D \geqslant 2$, the influence of the tower distance on the resistance coefficient of each direction is no longer obvious, but there is still a big difference in the resistance coefficient under different wind direction. Even if $\mathrm{L} / \mathrm{D} \geqslant 3$, twin Towers interference effects are still not negligible. 


\section{Conclusion}

In this paper, we study the table of the cooling tower and Twin Towers, and have the following conclusions:

Model of surface roughness for cooling tower appearance and wind pressure coefficient has great influence, and the roughness of the surface model, crosswind and suction is small, but wind and and the leeward pressure changed little.

When the model table and the roughness of $0.4 \mathrm{~mm}$ height, the measurement of the size of the point near the throat is very close to the standard, the previous test and test data, the roughness of the cooling tower as the most appropriate roughness of the Twin Towers interference effects.

At the top and the bottom of the cooling tower near the fault resistance coefficient was significantly greater than the central and towers of wind pressure interference effects along the height of the tower without significant changes. While ignoring the influence of the surrounding terrain and other buildings, on the overall drag coefficient mean as the indicator, the arrangement of the twin towers and when the landlord guide wind angle should be in 0 degrees to 40 degrees. At this time, when the $L / D \geqslant 1.5$ and towers respective resistance coefficient are slightly smaller than that of the single tower, but should note that $\beta$ is 22.5 degrees when the side of the tower before the larger lift coefficient.

\section{References}

[1] Wu Jike. Review and prospect about structural analysis of cooling towers. Mechanics in Engineering, 1996, 18(6): 1-5.

[2] Abu-Sitta S H. Hyperbolic cooling towers. Engineering Journal, 1973, 56(10): 26-28.

[3] Armitt J. Wind loading on cooling towers. Journal of the Structural Division, 1980, 106(3): 623-641.

[4] Niemann H J, Zerna W. Impact of research on development of large cooling towers. Engineering Structures, 1986, 8(2): 74-86.

[5] Basu P K, Gould P L. Cooling towers using measured wind data. Journal of the Structural Division, ASCE, 1980, 106(3): 579-600.

[6] Simiu E, Scanlan R H. Wind effects on structures. 3rd ed. New York: John Wiley \& Sons, 1996.

[7] Ruscheweyh H.Wind loadings on hyperbolic natural draught cooling towers. Journal of Wind Engineering and Industrial Aerodynamics, 1975, 1: 335-340.

[8] Sollenberger N J, Scanlan R H, Billington D P. Wind loading and response of cooling towers. Journal of the Structural Division, 1980, 106(3): 601-621.

[9] Kapania R K, Yang T Y. Time domain random wind response of cooling tower. Journal of Engineering Mechanics, 1984, 110(10): 1524-1543.

[10]Niemann H J. Wind effects on cooling-tower shells. Journal of the Structural Division, 1980, 106(3): 643-661. 